\title{
Effect of vitamin D combined with anti-tuberculosis drugs on serum IL-1 $\beta$, IFN-y and Th17 cell-associated cytokines for the management of spinal tuberculosis
}

\author{
Fang $\mathbf{Y u}^{1,2}$, Shen Cailiang ${ }^{3 *}$ \\ ${ }^{1}$ Department of Orthopedics, The First Affiliated Hospital of Anhui Medical University, Hefei City, ${ }^{2}$ Department of Orthopedics, \\ Zhejiang Ningbo PLA 113 Hospital, Ningbo City, ${ }^{3}$ Department of Spine Surgery, The First Affiliated Hospital of Anhui Medical \\ University, Hefei City, China
}

*For correspondence: Email: ph1169@163.com

Sent for review: 1 October 2018

Revised accepted: 21 April 2019

\begin{abstract}
Purpose: To investigate the effect of combination of vitamin $D$ and anti-tuberculosis drugs on serum interleukin-1 $\beta$ (IL-1 $\beta$ ), interferon- $\gamma$ (IFN- $\gamma$ ) and helper T 17 (Th17) cell-associated cytokine levels for the treatment of spinal tuberculosis (TB).

Methods: Ninety-two spinal TB patients were assigned without bias to two groups (46/group): study group (vitamin D combined with anti-TB drug group) and control group (anti-TB drug group). After treatment for 8 weeks, clinical effectiveness, adverse reactions, visual analog scale (VAS) score, spinal cord injury grade, and serum levels of IL-1 $\beta$, IFN- $\gamma$, Th17, IL-10, TGF- $\beta 1, I L-17$ and IL-23 were assayed with ELISA, and compared between groups.

Results: Study group total effectiveness was significantly higher than that in the control group (95.65\% vs $80.43 \%, p<0.05)$. Before drug administration, VAS score, degree of spinal cord injury and serum levels of IL-1 $\beta$, IFN- $-y, I L-10, T G F-\beta 1, I L-17$ and IL-23 were comparable in the study and control patients $(p>0.05)$. However, post-treatment, these parameters significantly decreased in both groups $(p<0.05)$, but were markedly lower in study group patients, relative to controls $(p<0.05)$.

Conclusion: The use of combined treatment of vitamin $D$ and anti-TB drugs is an effective and safe way to alleviate inflammatory response and improve the immunity of spinal TB patients via the regulation of the levels of Th17 cell-related factors.
\end{abstract}

Keywords: Vitamin D, Anti-tuberculosis drugs, Spinal tuberculosis, Clinical effectiveness, IL-1 $\beta$, IFN-y

\begin{abstract}
This is an Open Access article that uses a fund-ing model which does not charge readers or their institutions for access and distributed under the terms of the Creative Commons Attribution License (http://creativecommons.org/licenses/by/4.0) and the Budapest Open Access Initiative (http://www.budapestopenaccessinitiative.org/read), which permit unrestricted use, distribution, and reproduction in any medium, provided the original work is properly credited.
\end{abstract}

Tropical Journal of Pharmaceutical Research is indexed by Science Citation Index (SciSearch), Scopus, International Pharmaceutical Abstract, Chemical Abstracts, Embase, Index Copernicus, EBSCO, African Index Medicus, JournalSeek, Journal Citation Reports/Science Edition, Directory of Open Access Journals (DOAJ), African Journal Online, Bioline International, Open-J-Gate and Pharmacy Abstracts

\section{INTRODUCTION}

Spinal TB occurs more frequently than bone TB and joint TB, and accounts for $40-50 \%$ of TB cases [1]. Its clinical manifestations include waist back pain, muscle spasm and limited spinal activity. Severe cases result in spinal deformity, cold abscess and spinal bone destruction. Once the spinal cord and nerve are compressed, paraplegia occurs [2]. Clinically, anti-TB drugs 
are often used to treat spinal TB, but their therapeutic effects are limited, and they damage the liver. Thus, there is need for new and more efficacious therapeutic agents for TB. Studies have shown that vitamin $\mathrm{D}$, a kind of steroid hormone, possesses anti-TB properties: it regulates immunity and enhances the absorption of calcium and phosphorus, with certain effects on the treatment of TB [3, 4]. However, no studies have been carried out to investigate the effect of combination of vitamin $D$ and anti-TB drugs on serum IL-1 1 , IFN- $\gamma$ Th17), and the related factors IL-10, TGF- $\beta 1$ and IL-17 in TB patients. Moreover, the levels of IL-23 in patients with spinal TB is rarely reported. In the present study, vitamin D and anti-TB drugs were used in combination to treat patients with spinal TB. This was with a view to investigating the effect of the combined treatment on serum levels of IL-1 $\beta$ and IFN- $\gamma$, and the levels of Th17 cell-related factors IL-10, TGF- $\beta 1$, IL-17 and IL-23.

\section{EXPERIMENTAL}

\section{General information}

Ninety-two spinal TB patients were used as subjects in this study. This research was approved by the Ethical Committee of Department of Spine Surgery, The First Affiliated Hospital of Anhui Medical University, and carried out in line with Helsinki Declaration promulgated in 1964 as amended in 1996 [5].

\section{Inclusion criteria}

Table 1: Patient profile
The following category of patients were included: patients diagnosed with spinal TB through clinical manifestations, imaging examination and laboratory examination; patients without rheumatoid or rheumatism, and patients without TB and/or HIV. Other included patients were those who signed informed consent and those who tolerated the combined treatment.

\section{Exclusion criteria}

The following category of patients were excluded from the study: pregnant or lactating women; patients with spinal TB combined with hepatitis $B$, AIDS and other infectious diseases; and patients with spinal TB combined with malignant tumors. Others were spinal TB patients with severe heart, liver, lung and other organ dysfunctions; patients with speech defects or mental illness, and spinal TB patients with active TB in other areas. There were 92 included patients. These were randomly divided into study group $(n=46)$ and control group $(n=46)$. The study group comprised 25 men and 21 women with a mean age of $68.21 \pm 8.54$ years. For the control group, there were 24 females and 22 males, with a mean age of $67.41 \pm 8.43$ years. General data of subjects in both groups were comparable (Table 1).

\section{Treatments}

The control group was treated with oral administration of $5 \mathrm{mg} / \mathrm{kg}$ isoniazid tablets (antiTB drug, Shandong Xinyi Pharmaceutical Co. Ltd), National drug standard H37021458); oral $0.5 \mathrm{~g}$ rifampicin tablets (Shenyang Hongqi

\begin{tabular}{lcccc}
\hline Patient profile & $\begin{array}{c}\text { Study group } \\
(\mathbf{n}=\mathbf{4 6})\end{array}$ & $\begin{array}{c}\text { Control group } \\
(\mathbf{n}=\mathbf{4 6})\end{array}$ & $\boldsymbol{t} / \boldsymbol{X}^{2}$ & $\boldsymbol{P}$-value \\
\hline Age $($ mean \pm SD) & $68.21 \pm 8.54$ & $67.41 \pm 8.43$ & 0.452 & 0.652 \\
$\begin{array}{l}\text { Duration of disease } \\
\text { (mean } \pm \text { SD, years) }\end{array}$ & $2.09 \pm 0.72$ & $2.15 \pm 0.76$ & 0.389 & 0.698 \\
Gender $\{\mathrm{n}(\%)\}$ & & 0.392 & 0.532 \\
Male & $25(54.35)$ & $(47.83)$ & & 0.834 \\
Female & $21(45.65)$ & $24(52.17)$ & & \\
Lesions involving the vertebral & & & 0.044 & 0.845 \\
body $\{\mathrm{n}(\%)\}$ & $26(56.52)$ & $25(54.35)$ & & \\
1 & $20(43.48)$ & $21(45.65)$ & & \\
2 & & & \\
TB site $\{\mathrm{n}(\%)\}$ & $24(52.17)$ & $22(47.83)$ & & \\
Lumbar TB & $15(32.61)$ & $15(32.61)$ & & \\
Thoracic TB & $7(15.22)$ & $9(19.56)$ & & \\
Other vertebral bodies & & & \\
\hline
\end{tabular}


Pharmaceutical Co. Ltd, National drug standard Word H21021905); oral $15 \mathrm{mg} / \mathrm{kg}$ ethambutol (Henan Kelun Pharmaceutical Co., Ltd., National drug standard H41022316); and intramuscular injection of $1 \mathrm{~g}$ streptomycin sulfate (Shandong Lukang Pharmaceutical Co. Ltd, National drug standard H37020199), 2 times a week. All treatments were given daily. The study group received, in addition to control treatment, daily administration of 2 capsules of oral vitamin D drops (Henan Province Sinopharm Pharmaceutical Group Co. Ltd, National drug standard $\mathrm{H} 20056918)$. All treatments were given continuously for 8 weeks.

\section{Biochemical assays}

Fasting venous blood $(10 \mathrm{ml})$ was taken from each subject before and after treatment, and subjected to centrifugation for $15 \mathrm{~min}$ at 3000 rpm. The resultant serum samples were kept at $80^{\circ} \mathrm{C}$ prior to use for assay of IL-1 $\beta$, IFN- $\gamma$, IL-10, TGF- $\beta 1$, IL-17 and IL-23 with ELISA.

\section{Criteria for assessment}

\section{Clinical effectiveness}

The treatment effect was divided into four levels: cured, marked effective, effective, and ineffective. Cured implied absence of abscess, sinus and dead bone; normalized erythrocyte sedimentation, clear bone contour, and good condition of the general health of the patient. Markedly effective meant obvious improvements in abscess, body temperature and wounds; normalized erythrocyte sedimentation rate, and improvement in the patient's general condition. Effective: was used when there were some improvements in erythrocyte sedimentation rate, abscess, body temperature and wounds; absence of lesions and changes in general health of the patient. Treatment was ineffective if the symptoms recurred, with increased erythrocyte sedimentation rate, enlarged lesions, and no significant changes in the general condition of the patient. Total effectiveness was calculated as shown in Eq 1.

$T E(\%)=\frac{(C+M E+E)}{T} \times 100$

where $T E$ is total effectiveness, $C$ is cured, $M E$ is markedly effective, $E$ is effective, and $T$ is total number of cases.

\section{VAS scoring criteria}

The degree of pain in patients with spinal TB was assessed using a visual analogue scale [6,7].
Postoperative painlessness was scored 0 , mild pain was scored between 1 and 4, moderate pain was scored between 5 and 8 , and severe pain was scored 10 points. The higher the score, the higher the pain of spinal TB in the patient.

\section{Classification criteria of spinal cord injury}

Frankel spinal cord injury grading method was used to evaluate the degree of spinal cord injury in patients [8]. It comprises five grades: A, B, C, $\mathrm{D}$, and $\mathrm{E}$ (Table 2).

Table 2: Classification criteria for spinal cord injury

\begin{tabular}{|c|c|}
\hline Grade & Classification criteria for spinal injury \\
\hline A & $\begin{array}{l}\text { Complete disappearance of } \\
\text { feeling/sensation in the damage plane }\end{array}$ \\
\hline B & $\begin{array}{l}\text { Disappearance of most of the damage } \\
\text { below the damage plane, and only some } \\
\text { sacral areas have sensation }\end{array}$ \\
\hline C & $\begin{array}{l}\text { Loss of all useful functions below the } \\
\text { damage plane }\end{array}$ \\
\hline D & $\begin{array}{l}\text { Partial loss of muscle function below the } \\
\text { damage plane, leaving poor muscle motor } \\
\text { function }\end{array}$ \\
\hline $\mathrm{E}$ & $\begin{array}{l}\text { Feeling/sensation and good muscle function } \\
\text { with pathological reflexes }\end{array}$ \\
\hline
\end{tabular}

\section{Treatment indices}

Clinical effectiveness, adverse reactions, spinal cord injury grade, VAS score, serum IL-1 $\beta$, IFN-Y levels, and levels of Th17 cell-associated factors (IL-10, TGF- $\beta 1, \quad$ IL-17, IL-23 levels) were compared between the two groups.

\section{Statistical analysis}

Statistical analysis was performed with SPSS version 23.0. Clinical effectiveness and adverse reactions were compared between the two groups with Chi square $\left(X^{2}\right)$ test. The spinal cord injury grade, VAS score and serum IL-1 $\beta$, IFN- $\gamma$, IL- 10. TGF- $\beta 1$, IL-17 and IL-23 levels were compared using $t$-test. Values of $p<0.05$ were taken as indicative of statistically significant differences.

\section{RESULTS}

\section{Clinical effectiveness of treatments}

Table 3 shows that total effectiveness was markedly higher in the study group $(95.65 \%)$ than in control $(80.43 \%, p<0.05)$.

\section{VAS scores}

Trop J Pharm Res, May 2019; 18(5): 1143 
Table 4 shows that before treatment, VAS scores in the study and control groups were comparable Table 3: Clinical efficacy of treatments $(n, \%)$ $(p>0.05)$. However, post-treatment VAS scores

\begin{tabular}{lcccccc}
\hline Group & $\begin{array}{c}\text { Number of } \\
\text { cases }\end{array}$ & Cured & $\begin{array}{c}\text { Markedly } \\
\text { effective }\end{array}$ & Effective & Ineffective & $\begin{array}{c}\text { Total } \\
\text { effectiveness }\end{array}$ \\
\hline Study & 46 & $22(47.83)$ & $13(28.26)$ & $9(19.56)$ & $2(4.35)$ & $44(95.65)$ \\
Control & 46 & $15(32.61)$ & $12(26.09)$ & $10(21.74)$ & $9(19.56)$ & $37(80.43)$ \\
$X^{2}$ & & & & & & 5.060 \\
$P$-value & & & & & & 0.025 \\
\hline
\end{tabular}

Table 4: VAS scores (mean \pm SD)

\begin{tabular}{llc}
\hline Group & Time & VAS \\
\hline Control $(\mathrm{n}=46)$ & Before treatment & $8.09 \pm 1.12$ \\
& After treatment & $6.31 \pm 0.79^{\mathrm{a}}$ \\
Study $(\mathrm{n}=46)$ & Before treatment & $8.15 \pm 1.10$ \\
& After treatment & $4.08 \pm 0.68^{\mathrm{a}, \mathrm{b}}$ \\
\hline
\end{tabular}

${ }^{\mathrm{a}} P<0.05$, relative to pre-treatment value; ${ }^{\mathrm{a}, \mathrm{b}} p<0.05$, relative to control, post-treatment

were markedly lower than the pre-treatment values, but VAS score was higher in control subjects $(p<0.05)$.

\section{Spinal cord injury grades}

As can be seen in Table 5, pre-treatment classification of spinal cord injury between the two was comparable $(p>0.05)$. However, posttreatment scores of spinal cord injury in the two groups were markedly increased $(p<0.05)$. Moreover, after treatment, improvement in spinal cord injury in the study group was markedly enhanced, relative to the control group ( $p<$ 0.05).

Table 6 shows that before treatment, serum IL$1 \beta$ and IFN- $\gamma$ levels in both groups were comparable $(p>0.05)$. However, post-treatment serum IL-1 $\beta$ and IFN- $\gamma$ in the two groups were markedly less than their levels before treatment, but serum IL-1 $\beta$ and IFN- $\gamma$ in study group patients were markedly reduced, relative to the control group $(p>0.05)$.

\section{Levels of Th17 cell-related factors}

There were no significant differences in IL-10, TGF- $\beta 1$, IL- 17, IL-23 levels in both groups before treatment $(p>0.05)$. After treatment, the two groups had significant decreases in IL-10 and TGF- $\beta 1$, and IL-17 and IL-23 were also markedly reduced, relative to pre-treatment values $(p<$ 0.05 ). After treatment, IL-10, TGF- $\beta 1, \mathrm{IL}-17$ and IL-23 in the study group were less than their corresponding study group levels $(p<0.05)$. These results are shown in Table 7.

\section{Adverse reactions}

The results shown in Table 8 indicate that the incidence of undesirable reactions in the study group $(13.04 \%)$ was markedly reduced, when compared with control group $(28.26 \%, p<0.05)$.

\section{DISCUSSION}

Spinal TB is a chronic osteoarticular lesion associated with bone destruction. The incidence of spinal TB is highest in systemic bone and joint TB, accounting for $47.3 \%$. Most of the spinal TB is vertebral TB which accounts for $99 \%$. This is mainly caused by cancellous bone, wrong weight, increased strain, low muscle adhesion, poor blood supply and poor vertebral nourishment of the vertebral artery.

Table 5: Spinal cord injury grades (n)

\begin{tabular}{lcccccc}
\hline Group & Time & Class A & Class B & Class C & Class D & Class E \\
\hline Control $(n=46)$ & Before treatment & 0 & 0 & 5 & 27 & 14 \\
& After treatment & 0 & 0 & 1 & 20 & 25 \\
Study $(\mathrm{n}=46)$ & Before treatment & 0 & 0 & 3 & 27 & 16 \\
& After treatment & 0 & 0 & 0 & 16 & 30 \\
\hline
\end{tabular}

Table 6: Levels of IL-1 $\beta$ and IFN- $\gamma$ in serum

\begin{tabular}{llrc}
\hline Group & Time & IL-1 $\beta$ (pg/mL) & IFN-y $(\mathbf{p g} / \mathbf{m L})$ \\
\hline Control $(n=46)$ & Before treatment & $10.11 \pm 2.41$ & $51.82 \pm 11.70$ \\
& After treatment & $8.19 \pm 1.11^{1}$ & $44.20 \pm 9.79^{\mathrm{a}}$ \\
Study $(\mathrm{n}=46)$ & Before treatment & $10.18 \pm 2.39$ & $53.49 \pm 12.38$ \\
\hline
\end{tabular}




\begin{tabular}{ccc}
\hline After treatment & $4.90 \pm 0.92^{1,2}$ & $35.21 \pm 7.48^{\mathrm{a}, \mathrm{b}}$ \\
\hline${ }^{\mathrm{a}} P<0.05$, relative to pre-treatment value; ${ }^{\mathrm{a}, \mathrm{b}} p<0.05$, relative to control, post-treatment
\end{tabular}

Table 7: Th17 cell-related factor levels

\begin{tabular}{llcccc}
\hline Group & Time & IL-10 $(\mathbf{p g} / \mathbf{m L})$ & TGF- $\beta_{1}(\mu \mathbf{g} / \mathbf{L})$ & IL-17 $(\mathbf{p g} / \mathbf{m L})$ & IL-23 $(\mathbf{p g} / \mathbf{m L})$ \\
\hline $\begin{array}{l}\text { Study } \\
(\mathrm{n}=46)\end{array}$ & Before treatment & $35.19 \pm 5.71$ & $79.61 \pm 10.41$ & $102.59 \pm 10.41$ & $757.42 \pm 102.54$ \\
& After treatment & $15.61 \pm 10.51^{1,2}$ & $43.79 \pm 19.62^{1,2}$ & $45.61 \pm 36.78^{1,2}$ & $312.77 \pm 271.12^{1,2}$ \\
Control & & & & \\
$(\mathrm{n}=46)$ & Before treatment & $34.88 \pm 5.69$ & $80.11 \pm 10.22$ & $103.32 \pm 10.52$ & $752.16 \pm 101.35$ \\
& After treatment & $24.79 \pm 23.19^{1}$ & $56.10 \pm 24.41^{1}$ & $77.51 \pm 37.19^{1}$ & $482.36 \pm 283.55^{1}$ \\
\hline${ }^{a} P<0.05$, relative to pre-treatment value; ${ }^{\mathrm{a}, \mathrm{b}} p<0.05$, relative to control, post-treatment &
\end{tabular}

Table 8: Incidence of adverse reaction ( $\mathrm{n}, \%)$

\begin{tabular}{lccccc}
\hline Group & $\begin{array}{c}\text { Gastrointestinal } \\
\text { discomfort }\end{array}$ & $\begin{array}{c}\text { Lower limb } \\
\text { numbness }\end{array}$ & Vision loss & Tinnitus & $\begin{array}{c}\text { Total adverse } \\
\text { reactions }\end{array}$ \\
\hline Study $(\mathrm{n}=46)$ & $2(4.35)$ & $1(2.17)$ & $1(2.17)$ & $2(4.35)$ & $5(13.04)$ \\
Control $(\mathrm{n}=46)$ & $6(13.04)$ & $2(4.35)$ & $2(4.35)$ & $3(6.52)$ & $13(28.26)$ \\
$X^{K}$ & & & & & 4.420 \\
$P$-value & & & & & 0.036 \\
\hline
\end{tabular}

\section{IL-1 $\beta$ and IFN- $\gamma$ levels in serum}

Spinal TB is secondary to lymphatic TB and lung TB. Tubercle bacilli causes tuberculosis which can be transmitted to the whole body through the blood after infection of the lungs and lymph nodes, leading to complications such as spinal infection, TB pleurisy and TB meningitis [9]. At present, there are many types of anti-TBs drugs used in clinical practice, including isoniazid, pyrazinamide, rifampicin and aminosalicylic acid. These drugs are highly selective for Mycobacterium tuberculosis and have strong antibacterial activities. However, they are limited in treatment effectiveness, and they are associated with numerous side effects.

Studies have shown that patients receiving antiTB drugs have a reversible and moderate elevations in transaminases (15 - 30\%) and about $2 \%$ incidents of liver function damage [10]. Studies have also shown that the combination of vitamin $D$ and anti-TB drugs can delay drug resistance and enhance treatment effectiveness [11]. Related literature reports that lack of vitamin $D$ is an independent pre-disposing factor for TB; vitamin $D$ enhances resistance to TB infection, regulates the immune system and calcium metabolism, and exerts therapeutic effect on spinal TB [12].

In the present study, the total effectiveness in the study group given anti-TB drug and vitamin D $(95.65 \%)$ was markedly higher than the total effectiveness in control subjects (80.43\%). Adverse reactions in the study group (13.04\%) were markedly less than those in control patients
(28.26\%). Moreover, VAS score and the degree of spinal cord injury were markedly lower in the study group. Thus, the combination of vitamin D and anti-TB drugs is safe, and it can also effectively inhibit the growth of Mycobacterium tuberculosis, and reduce pain and spinal cord injury. Vitamin D probably exerted this therapeutic effect by inhibiting the growth of bacilli through activation of the cellular immune system, thereby improving the body's ability to resist Mycobacterium tuberculosis.

It is known that IL-1 $\beta$, an inflammation-promoting factor, is involved in wide range of pathological damage processes such as human tissue destruction and edema formation. At the same time, IL-1 $\beta$ can promote the proliferation and differentiation of $B$ lymphocytes and the production of immunoglobulins. Studies have shown that IFN- $y$, a lymphokine with extensive immunomodulatory effects, modulates immune responses by interfering with immune-related gene transcription. When acute infectious diseases occur, the body's immune system is activated and IFN-y secretion increases in vivo [13]. It has been reported that Th17 cytokines participate in TB-associated immune responses by regulating the levels of IL-10, TGF- $\beta 1$, IL-17, IL-23 and other active factors [14]. Moreover, IL10 is a multifunctional negative regulator produced by macrophages, and activated B cells and monocytes. It is involved in the biological regulation of various cells such as immune cells and inflammatory cells. It is also involved in highly infectious diseases and autoimmunity. As a negative regulator of polypeptide cell growth, TGF- $\beta 1$ binds to the corresponding receptor and 
regulates cells by mediating the Smad3 signaling pathway, and it is involved in inflammation, angiogenesis, immune-activated cell proliferation, lymphocyte differentiation, and wounds.

Various pathophysiological processes such as repair and organ fibrosis are closely related [15]. It has been revealed that IFN- $\gamma$ can inhibit the phosphorylation of TGF- $\beta$ downstream signal transduction factor Smad3, block the effect of Smad3 on TGF- $\beta$ receptor, and then interfere with TGF- $\beta$-induced Th17 cell differentiation [16]. Indeed, IL-17 is an early initiation factor of T cellinduced inflammatory responses, and it is involved in defense against infection. It can induce and regulate multiple immune responses in the body. IL-23 is a heterodimeric cytokine produced by activated macrophages and dendritic cells, which acts mainly on Th17 cells and promotes the production of IL-17A, IL-17F, IL-22 and other cells by Th17 cells.

Studies have shown that IL-23 can mediate the phosphorylation process of STAT3, activate STAT3 and promote IL-17 secretion [17]. This study revealed that the levels of serum IL-1 $\beta$, IFN- $\gamma$, IL-10, TGF- $\beta 1$, IL-17 and IL-23 in the two groups were significantly lower than their corresponding values prior to treatment, and the serum levels of IL-1 $\beta$, IFN- $\gamma$, IL-10, TGF- $\beta 1$, IL17, IL-23 were significantly lower in the study group than in the control group. These results may be due to the fact that Mycobacterium tuberculosis enters the body through the respiratory tract, digestive tract, damaged skin and mucous membranes, thereby triggering an inflammatory reaction and increasing the secretion of inflammatory factors such as IL-1 $\beta$ and IFN- $\gamma$. These induce damage through delayed allergic reaction. The results of this study show that combined treatment with vitamin $D$ and TB drugs can reduce the suppression of immune and inflammatory response by regulating the levels of IL-1 $\beta$, IFN- $\gamma$ and Th17 cell-related factors, thereby alleviating spinal injury and clinical symptoms due to spinal TB.

\section{CONCLUSION}

The results obtained in this study demonstrate that a combination of vitamin $D$ and anti-TB drugs has significant and beneficial effects on patients with spinal TB. The combined treatment is safe, and also reduces inflammatory response by regulating the levels of Th17 cell-related factors, while improving the immunity of the patients.

\section{DECLARATIONS}

\section{Conflict of interest}

No conflict of interest is associated with this work.

\section{Contribution of authors}

We declare that this work was done by the authors named in this article and all liabilities pertaining to claims relating to the content of this article will be borne by the authors. Shen Cailiang conceived and designed the study, Fang Yu, Shen Cailiang collected and analysed the data, Fang Yu wrote the manuscript.

\section{Open Access}

This is an Open Access article that uses a funding model which does not charge readers or their institutions for access and distributed under the terms of the Creative Commons Attribution License (http://creativecommons.org/licenses/by/ 4.0) and the Budapest Open Access Initiative (http://www.budapestopenaccessinitiative.org/rea d), which permit unrestricted use, distribution, and reproduction in any medium, provided the original work is properly credited.

\section{REFERENCES}

1. Tang $L$, Bao YC, Gao RX, Han CF, Sun $X C$, Zhang $W L$, Feng $S Q$. The relation between vitamin $D$ deficiency and susceptibility to spinal tuberculosis. Tianjin Med J 2017; 44(12): 1492-1495.

2. Jiang Z, Qu MY, Wan K. Retrospective study of drugresistant spinal tuberculosis and efficacy of clinical treatment. China J Modern Medicine 2016; 26(11): 132136.

3. Yang CY, Hu JC, Liu YW, Ma Y, Yang LY. Effect of Vitamin $D$ Combined with Anti Tuberculosis Drugs on the Serum Levels of IL-1 and Interferon Gamma of Elderly Patients with Spinal Tuberculosis. Prog Mod Biomed 2017; 17(9): 1707-1709.

4. Han JF. The Mechanism and Significance of Vitamin D for Treatment of Tuberculosis. Med Recapitulate 2015; 21(24): 4517-4520.

5. World Health Organization. Declaration of Helsinki. Br Med J 1996; 313(7070): 1448-1449.

6. Yao LM, Zhao Q, Liu FS, Li Z, Dong ZL, Jia CG. Clinical study on the therapeutic scheme and curative effect of retreating postoperative spinal tuberculosis. J Hebei Med Univ 2016; 37(5): 550-554.

7. Zhao $X Q$, Guan $Y L$, Wang ZD, Lai PY. Spinal tuberculosis treatment via isolated posterior approach for focal debridement and inter-nal fixation of bone grafting fusion. J Clin Orthop 2016; 19(6): 660-663. 
8. Li N, Ai JC. Clinical Curative Effect of Posterior Lesion Removal, Intervertebral Bone Grafting and Stapled Rod Internal Fixation for the Treatment of Apinal Tuberculosis in the Thoracic Lumbar Segment. Med Recapitulate 2018; (7): 1440-1443.

9. Chen $X$, Huang YJ, Tian $Q$, Xue $C$, Li HP. Biocompatibility of titanium alloy and stainless steel internal fixation materials in the treatment of spinal tuberculosis. J Clin Rehabil Tissue Eng Res 2015; 19(30): 4860-4864.

10. Alam MS, Phan K, Karim R, Jonayed SA, Munir HK, Chakraborty S, Alam T. Surgery for spinal tuberculosis: a multi-center experience of 582 cases. J Spine Surg 2016; 1(1): 65-71.

11. Guan BY, A H, He Y, Zhu B, Lei DQ. Study on the clinical effect of surgical combined with anti-tuberculosis drugs in the treatment of elderly patients with spinal tube. Clin Med China 2016; 32(6): 496-498.

12. Yu Ruiming, Gao Y, Yan TH. Clinical Efficacy of Thymopoietin Combined with the Conventional Anti Tuberculosis Drugs in the Treatment of Drug Resistant Tuberculosis. China Health Stand Manag 2016; 7(20): 139-141.
13. Salahuddin N, Ali F, Hasan Z, Rao N, Aqeel M, Mahmood $F$. Vitamin $D$ accelerates clinical recovery from tuberculosis: results of the SUCCINCT Study [Supplementary Cholecalciferol in recovery from tuberculosis]. A randomized, placebo-controlled, clinical trial of vitamin $D$ supplementation in patients with pulmonary. BMC Infect Dis 2013; 13(1): 22.

14. Sun L, Li Y, Jia X, Wang Q, Li Y, Hu MH, Tian LL, Yang JF, Xing WJ, Zhang WH, et al. Neuroprotection by IFN-Y via astrocyte-secreted IL-6 in acute neuroinflammation. Oncotarget 2017; 8(25): 40065-40078.

15. Cheng T, Wu WL, Huang H. Clinical study of Th1/Th2/Treg/Th17 immune response in patients with tuberculosis. China Med Herald 2017; 14(26): 109-112.

16. Geginat J, Paroni M, Kastirr I, Larghi P, Pagani M, Abrignani S. Reverse plasticity: TGF-ßand IL-6 induce Th1-to-Th17-cell transdifferentiation in the gut. Eur $\mathrm{J}$ Immunol 2016; 46(10): 2306-2310.

17. Tang Q, Li J, Zhu H, Li P, Zou Z, Xiao Y. Hmgb1-IL-23IL-17-IL-6-Stat3 axis promotes tumor growth in murine models of melanoma. Mediators Inflamm 2013; 2013(2013): 713859. 